\title{
Current understanding of PrnP Genetics: A tool for Molecular Assisted Selection in Sheep Populations (A review)
}

\author{
Viorica COSIER*, Stelian DARABAN \\ Faculty of Animal Science and Biotechnologies, University of Agricultural Sciences and Veterinary \\ Medicine, 3-5 Mănăştur Street, 400372 Cluj-Napoca, Romania \\ *Corresponding authors, e-mail: viorica.cosier@gmail.com
}

Bulletin UASVM Animal Science and Biotechnologies 73(1)/ 2016

Print ISSN 1843-5262; Electronic ISSN 1843-536X

DOI:10.15835/buasvmcn-asb: 11976

\begin{abstract}
Scrapie is a neurodegenerative prion disease of sheep, goats and mouflons, belonging to the group of transmissible spongiform encephalopathies (TSEs), which affects humans as well. Even though classical scrapie has been known for over 250 years, the 1985 BSE crisis related to the advent of new forms of the Creutzfeldt-Jakob disease (VCJD) in humans imposed the implementation of rapid coercive legal measures of prevention, control and eradication of TSEs. According to the prion hypothesis, the transmissible agent is the pathological isoform ( $\mathrm{PrP}^{\mathrm{Sc}}$ ) of cellular prion protein $\left(\mathrm{PrP}^{\mathrm{C}}\right)$. Specific polymorphisms of the gene that encodes cell prion protein (PrnP) in sheep have been associated with resistance / natural susceptibility to the development and progression of the disease. Combinations of alleles at three adjacent codons (136 [A/V], 154 [H/R], 171 [H/Q/R]) underpin the classification of 15 possible genotypes in risk classes, applicable in selection schemes where the maximum resistance is conferred by ARR allele, and the minimum by the VRQ allele. Although, after applying these programmes, the genetic structure of sheep populations has changed favourably, genotype association studies showed that no genotype is completely resistant to the infection, including homozygote ARR / ARR. With the discovery of atypical scrapie (Nor98), it became evident that the connection between the genetics of prion protein gene polymorphisms and susceptibility to the disease must be re-evaluated individually for each breed. In scrapie monitoring and control programmes, three diagnostic categories of the disease are observed: classical scrapie, atypical scrapie and BSE scrapie in small ruminant. This review shows the chronology of progress in the fight for the eradication of TSEs in sheep, 30 years after the BSE epidemic outburst, focusing especially on the link between the molecular diagnostic forms and the genetics of the disease.
\end{abstract}

Keywords: TSEs, prion diseases, scrapie, PrnP polymorphism, PrP,

\section{INTRODUCTION}

Transmissible spongiform encephalopathies (TSEs) are a group of prion diseases which includes: Creutzfeldt-Jakob disease (CJD), kuru, Gerstmann-Sträussler-Scheinker Syndrome (GSS), and fatal Familial Insomnia (FFI) in humans, as well as scrapie in sheep, goats and mouflons, Bovine Spongiform Encephalopathy (BSE) in cattle, Chronic Wasting Disease (CWD) in cervids, Feline Spongiform Encephalopathy (FSE) in cats, encephalopathies in mink, exotic ungulates and lemurs (Liberski and Jaskólski, 2002).
According to the prion hypothesis, it is believed that the causative agents of the disease in the TSE group are prions, infectious protein molecules lacking nucleic acids. All diseases in the group are neurodegenerative and lethal, caused by the accumulation of abnormal prion protein aggregates in nerve tissues, relatively stable to proteolysis, spongiform vacuolation and gliosis. Today it is widely accepted that the infectious agent is the pathological isoform of the normal prion protein - $\mathrm{PrP}^{\mathrm{C}}$, encoded by the gene PrnP. Normal cellular protein is converted to its pathological 
isoform PrPSc through a posttranslational process during which it acquires the $\beta$ sheet conformation (Prusiner, 1998).

Classical scrapie is a sporadic transmissible spongiform encephalopathy of sheep and goats, which was first reported in England and then in Germany and France, over 200 years ago (Detwiler et al., 2003). Since then, the spread of the disease occurred mainly through trade and movement of the infected sheep in all EU countries, but also in Canada, the USA, Asia and Africa. Only Australia and New Zealand are considered free from scrapie, and this is not due to lack of predisposition to the disease of the sheep, but to imposing firm restrictions on imports of sheep and other coercive control measures (Hunter and Cairns, 1998; *** , 2016).

Even if scrapie is not really a genetic disease, susceptibility to scrapie may be under the influence of genes (Hope, 2000).

Since 2002, all EU countries have been compelled to implement programmes to increase resistance to scrapie, as part of measures to eradicate TSE nationwide (2002/1003 / EC:Commission Decision). This review aims to highlight progress in the fight for the eradication of TSEs in sheep, regulated at European level, focusing especially on the link between the molecular diagnostic forms and the genetics of the disease.

\section{Context}

The decision came after the outburst of the BSE epidemic in the UK in 1985 (Wells et al., 1987) when there first appeared worries that BSE could be transmitted to other species using feeds containing meat and bone meal (MBM) from infected animals, and also to humans. It was later proven that the concerns were justified, as the first cases of a new form of Creutzfeldt-Jakob disease were diagnosed and confirmed in humans - vCJD - (Will et al., 1996, Will, 2003; Collinge et al., 1996; Bruce et al., 1997; 1998; 2003; Scott, 1993) as a result of consumption of BSE-infected meat (Wilesmith et al., 1991). During the BSE epidemic episodes, domestic cats, as well as big cats and exotic ruminants in captivity were exposed to and infected with the BSE agent through the ingestion of MBM obtained from sick animals (Baylis, 2002; Peet and Curran, 1992; Willoughby 1992; Foster et al., 1993; Sigurdson, 2011; Bencsik et al., 2009; Eiden et al., 2010). Amidst this situation, the first measures taken by the EU Commission were banning MBM (94/381 / EC: Commission Decision), banning exports of beef from the UK (96/239 / EC: Commission Decision) and definition of a strategy which could highlight the presence of the infectious agent of BSE in small ruminants.

Although for over 250 years there were no reported cases of transmission of classical scrapie to humans (Schneider et al., 2008), uncertainties related to the species barrier (Bruce et al., 1994) led many countries to develop policies to eliminate all animals infected with TSEs from the food chain (Heaton et al., 2011).

So far there have not been reports of natural infection of sheep with the BSE agent, but ithas been shown that sheep are susceptible to experimental infection with BSE, via oral, intravenous and intracerebral routes (Foster, et al., 1993; Jeffrey et al., 2001; Ferguson et al., 2002; Bellworthy et al., 2005a; Gonzalez et al., 2005). After intracerebral inoculation with the BSE agent, infectivity spreads throughout the lymphoid tissues and then throughout the entire carcass. Therefore, it would make all mutton and derivatives much more dangerous for humans (van Keulen et al., 2008). With the occurrence of new atypical forms of BSE in cows (types L and H) (Casalone et al., 2004; Buschmann et al., 2004 a; Capobianco et al., 2007; Beringue et al., 2006, Beringue et al., 2007, Baron et al., 2011), the hypothesis was formulated according to which BSE epidemic would originate from the recycling of the agent of the atypical BSE form (type L), after a first cross-species transmission to an intermediary host, which could be sheep (Wilesmith et al, 1988; 1991; Baron et al., 1999; Baron et al., 2000; 2006; Capobianco et al., 2007). Concerns about the possibility of BSE transmission to sheep and goats, and the discovery of two cases of natural infection with BSE in goats (Eloit et al., 2005; Jeffrey et al., 2006) prompted the European Commission to increase the search for BSE presence in small ruminants.

In addition, an unusual type of scrapie was identified for the first time in Norway in sheep, in 1998, and was therefore designated as scrapie Nor98 or Atypical scrapie (Benestad et al., 2003).

In 2011 the conclusions of the EFSA Commission were that the only zoonotic prion agent is the classical BSE agent and, for the atypical scrapie agent, the epidemiological data 
are insufficient to conclude that the agent has a zoonotic potential. However experimental transmission of prion agents to human PrP transgenic mice and primates led to the conclusion that other infectious agents of TSEs have zoonotic potential (i.e. L-type Atypical BSE agent that has similar or even higher potential than the classical BSE agent) (EFSA, 2011).

Since the implementation in Europe of a large surveillance program for TSE in small ruminants, at least three distinct types of scrapie agents have been identified/isolated in the natural host: SSBP/1 (Dickinson et al., 1968 a,b), CH1641 (Foster and Dickinson, 1988), and atypical scrapie agent-Nor98 (Benestad et al., 2003; Simmons et al., 2007; 2011) (cited by EFSA Report, 2011).

In an attempt to make programmes to eliminate TSE most efficient, EFSA published a classification of TSE in small ruminants, which it divided into three diagnostic categories as follows: classical scrapie, atypical scrapie, including the type Nor98, and BSE scrapie of small ruminant; discrimination between BSE in sheep and scrapie has been mandatory since 2005 (Commission Regulation (EC) No 36/2005). The distinctive features of the infectious agents involved in TSEs in sheep can be determined based on the molecular profile of the modified prion protein $\mathrm{PrP}^{\mathrm{Sc}}$ by using the Western blotting analysis, after digestion with proteinase $\mathrm{K}$, and also by means of affinity to various antibodies (Stack et al., 2002; 2009).

In sheep, classical scrapie susceptibility or resistance was associated with polymorphisms in codons 136, 154 and 171 in the ORF area of 236 codons of the PrnP gene (Hunter et al., 1991). Based on the three codons' polymorphisms that form haplotypes with linked transmission, since 2003 in the EU scrapie eradication strategies have been implemented based on molecular assisted selection (Commission Decision 2003/100/ EC). The regulation provides for the selection of the ARR haplotype associated with maximum resistance to the progress of the disease and the elimination VRQ alleles in populations, alleles that confer maximum susceptibility to the disease.

If the first selection programmes to increase resistance to scrapie were based predominantly on alleles in the three codons, shortly, in the extensive surveillance and control process of TSEs started in European countries and beyond, atypical scrapie forms, such as the Nor98 were detected in some animals ARR / ARR (Groshup et al., 2007; Jeffrey et al., 2014). Moreover, also in case of experimental transmission of the classical scrapie and BSE agent, ARR / ARR genotype did not appear totally resistant to infection (Buschmann et al., 2004b; Luhken et al., 2007), but other polymorphisms, from other codons (F141L, M112T, M137T, P168L and $\mathrm{N} 176 \mathrm{~K}$ ) were tested in association procedures on resistance to infection with atypical forms of scrapie agent, including the type Nor98 and BSE, in different breeds (Moum et al., 2005; Heaton et al., 2010). Study results show that susceptible genotypes, characteristic of atypical scrapie, are different from classical scrapie and that subtypes of codon 141 (L / F) in certain combination with haplotypes of codons 136/154/171: ALHQ AFRQ and ARR are most often affected (Benestad et al., 2008).

This new evidence caused concern for the implementation of selection programmes for increased resistance to classical scrapie and led to reconsidering associations between polymorphisms of PRNP gene in each breed. The first effect of these discoveries was the inclusion of codon 141 in genotyping programmes, along with the three codons 136/154 and 171.

Adopting cautious approaches or even different methods was suggested for breeds in conservation and in those where the ARR allele is absent in populations, or it occurs infrequently. In this context, application of molecularly assisted selection needs to be reviewed for every breed. For example in Suffolk sheep in the UK, where the VRQ allele is rare, genotype ARQ / ARQ is the most sensitive to classical scrapie (Laegreid et al., 2008), but subtype M112T of genotype ARQ / ARQ (MARQ/TARQ and TARQ/TARQ) shows a longer incubation at intracerebral challenge with BSE while in the carriers of alleles ARR (ARQ / ARR and ARR / ARR) incubation and survival time increases further (Houston et al., 2015). Breeds with genotype VRQ / VRQ are the most sensitive to scrapie, followed by the combination of VRQ allele with ARQ allele (Bossers et al., 1999; O'Doherty et al., 2002).

After the application of measures for prevention, control and eradication of TSE in Europe, from 1992 to 2010, cases of BSE fell from 37,322 to 45 , and the number of sheep and goats tested and suspected of TSE fell from 2,753 in 2002 to 759 in 2010 in sheep, and from a maximum of 
1,560 in 2005 to 1,110 in 2010 in goats. Cases that were considered suspicious in 2010, both of sheep and goats, were subjected to discriminatory tests, and no case of infection with the BSE agent was recorded $(* * *, 2010)$.

\section{Ovine Transmissible Spongiform Encephalopathies (TSEs)}

All prion diseases including scrapie are fatal diseases that affect the nervous system, characterized by vacuolation, gliosis and accumulation of abnormal forms of prion protein $\operatorname{Prp}^{\mathrm{Sc}}$ in the brain, progressive loss of neurons and the absence of classical inflammation (Kovacs, 2005).

Scrapie also known as tremblante, traberkrankheit, prurigo lombar or rida had been recognised for at least 250 years but the transmissibility was demonstrated by Cuille and Chele in 1938, when the disease had been reproduced by intraocular inoculation of healthy sheep with a preparation of spinal cord from an affected sheep (Campeanu, 2001). Since the discovery of the disease and to date, several forms of scrapie have been described that can be discriminated in distinct molecular TSE types, based on the electrophoretic profile of the modified prion protein $\left(\mathrm{PrP}^{\mathrm{Sc}}\right)$ in Western blot analysis following treatment with Proteinase $\mathrm{K}$ (PK). These are: classical scrapie, atypical scrapie and BSE scrapie in small ruminants.

Confirmatory diagnosis in classical scrapie is done by detecting neuronal vacuolation, degeneration in the central nervous system that can be highlighted on tissue fixed in formalin and immunohistochemical methods for detection of modified prion protein $\mathrm{PrP}^{\mathrm{Sc}}$ in the brain of affected sheep and in lymphoreticular tissues. The immunohistochemical detection methods of $\mathrm{PrP}^{\mathrm{Sc}}$ are also useful to identify sheep in the preclinical stage of the disease because $\mathrm{PrP}^{\mathrm{Sc}}$ accumulates in the peripheral lymphoid nodes, long before accumulation in the central nervous system and in early clinical stages (O' Rourke et al., 1998) when histological changes caused by the disease are underrepresented (Andreoletti et al., 2000). All these changes are not identical in other forms of scrapie.

\section{Classical scrapie}

Clinical signs in classical scrapie usually begin insidiously, often with behavioural changes that become apparent after several inspections. Although the clinical image may vary from case to case, several major signs appear predominantly such as: behaviour changes, and sensory and locomotor impairments (Konold et al., 2007; Hunter, 2003).

Clinical, scrapie should be suspected in animals that develop a slow walk and nervous signs. Pruritus strengthens the diagnostic, but the absence of pruritus does not rule it out (Catoi et al., 2008). Animals become indifferent or overly attentive to the stimuli around, appear to be confused and sometimes aggressive, lose their gregarious instinct and separate from the herd. Ataxia is common, manifest in tremors and convulsions (Capuchio et al., 2001; Foster and Hunter, 1998; OIE, 2009). Simultaneously or later, signs of paresthesia manifested as pruritus caused by rubbing the lower dorsal area appear, the animal taking an upright characteristic position and showing the characteristic "nibble reflex" (Konold et al., 2007; Brown, 2005). This behaviour causes pronounced depilation and skin lesions, most frequently in the dorsal region, rarely head or forelimbs. In the final stages of the disease, although the appetite may appear normal, the animals lose the ability to feed themselves and the condition degenerates (Hunter, 2003).

Classical scrapie is characterized by transmission under natural conditions. It is generally assumed that neuroinvasion results from infection of the enteric nervous system neurons subsequent to amplification of infectivity in lymphoid tissues and later spread via sympathetic and parasympathetic pathways (Jeffrey and Gonzalez, 2007). The incubation period of scrapie agent is 2-5 years and death occurs within 2 weeks to 6 months after clinical onset. Scrapie can be recognized in herds based on clinical signs, combined with the history of the animal. The clinical diagnosis is confirmed by detection of neuronal and neuropil vacuolation (Fig.1 and 2) in microscopic examination of the target tissue sections, characterised by spongiform vacuolation, astrogliosis and the deposition of $\mathrm{PrP}^{\mathrm{Sc}}$ amyloid plaques in the central nervous system (CNS) (Fig $3)$.

Scrapie is diagnosed routinely by immunohistologic examination for the detection of $\mathrm{PrP}^{\mathrm{Sc}}$ accumulation in the brain and of lymphoreticular tissues from infected animals. In classical scrapie 
the lesions in the Central Nervous System (CNS) are grey matter vacuolation immunolabelling in the medulla oblonga, involving the dorsal motor nucleus of the vagus (DMNV) and also the spinal tract of the trigeminal nerve. Because in classical ovine scrapie, deposition of $\mathrm{PrP}^{\mathrm{Sc}}$ in the lymphoreticular system precedes accumulation in the central nervous system, immunohistochemical methods of $\mathrm{PrP}^{\mathrm{Sc}}$ detection are often useful to identify sheep in a preclinical stage of the disease (0 Rourke et al., 1998), when the histological changes caused by the disease are underrepresented (Andreoletti et al., 2000). In this respect, $\mathrm{PrP}^{\mathrm{Sc}}$ has been detected in tonsils and retropharyngeal lymph nodes, nictitating

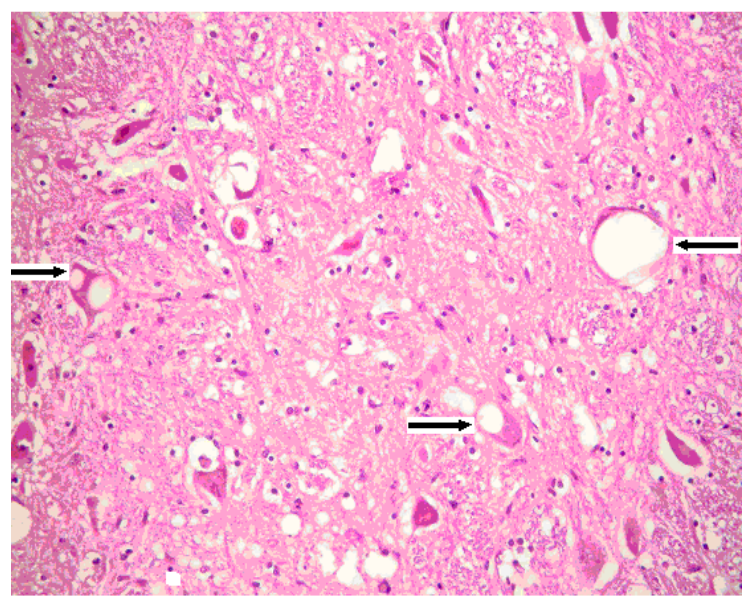

Fig. 1 Bridge of Varolio: vacuolation of neurons (black arrow) (original)

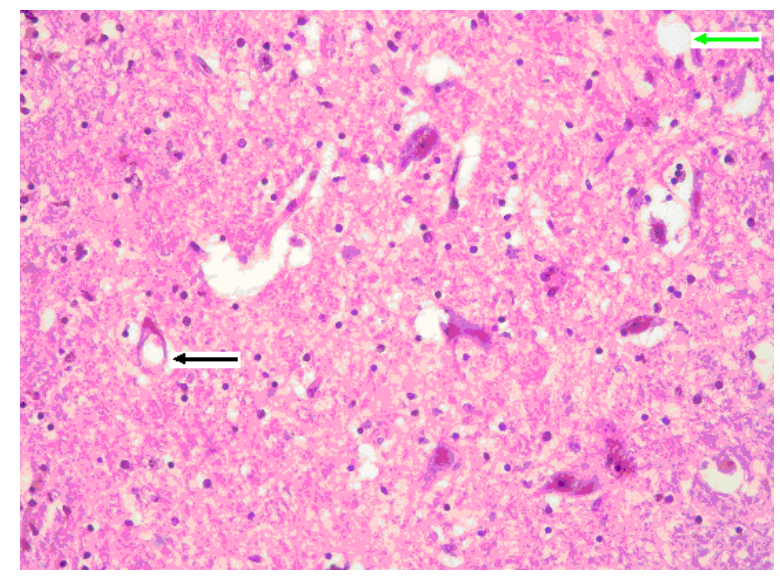

Fig 3. Cerebral peduncles: vacuolation of neuropil (green arrow), vacuolation of neurons (black arrow), gliosis (original) membrane (Fig. 4), spleen, muscles, placentas, distal ileum and proximal colon.

In recent years rapid tests were developed for post-mortem diagnosis of scrapie, which are based on $\mathrm{PrP}^{\mathrm{Sc}}$ detection, resistant to proteolysis (PK) to facilitate active surveillance of the disease in herds (Gavier-Widen et al., 2005).

The biochemical feature in classical scrapie is the typical $\mathrm{PrP}^{27-30}$ profile of the prion protein following treatment at all concentrations of $K$ proteinase, i.e three bands corresponding to $\mathrm{N}$-terminally truncated diglycosylated, monoglycosylated and non-glycosylated PrPres (Oesch et al.,1985; Pirisinu et al., 2013).

In genetic terms, polymorphism of prion protein gene from the three codons, 136154

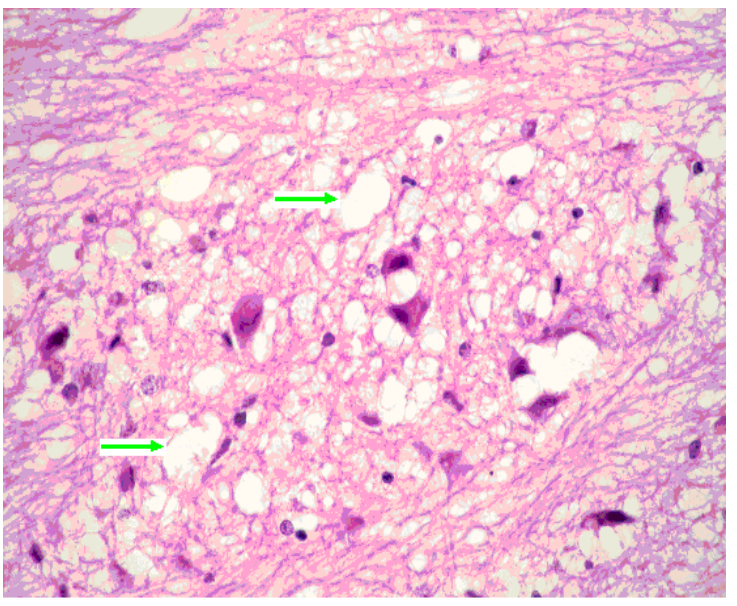

Fig. 2 Bridge of Varolio: vacuolation of neuropil (green arrow) (original)

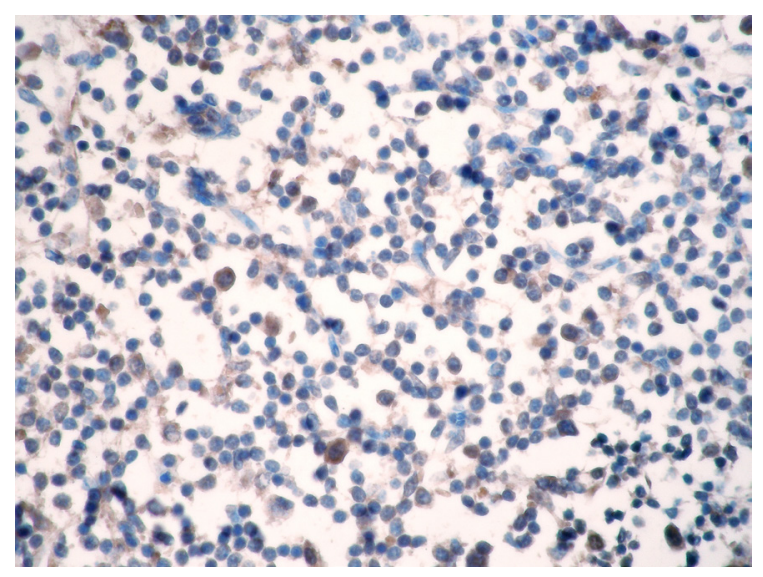

Fig 4. Lymphoid tissue negative for $\mathrm{PrP}^{\mathrm{Sc}}$, weak reaction for $\operatorname{PrP}$ ( original) 
and 171, with five alleles prevalent in European populations (ARR, ARQ, AHQ ARH, VRQ) strongly influence resistance or susceptibility to classical scrapie, with two versions showing extreme associations in most European breeds: ARR haplotype that confers the highest resistance and VRQ haplotype associated with the highest susceptibility. However, there are exceptions, for example in Suffolk breed there are only three predominant genotypes (absent VRQ / VRQ), and maximum susceptibility occurs in homozygotes ARQ / ARQ (Goldman et al., 1990; Westaway et al.1994), compared to the Texel breed in which all possible genotypes are recorded. Romanian sheep breeds also record the presence of all five alleles, but some appear with very low frequencies in populations (e.g., VRH, VHQ) (Cosier et al., 2011).

\section{Atypical scrapie (Nor98)}

An atypical form of scrapie was first diagnosed in Norway in 1998 and was therefore called Nor98 (Benestad et al., 2003). Identification of the disease in Europe was made possible with the implementation of programmes of active surveillance of TSEs in small ruminants; since then, cases have been reported from almost all European countries (Belgium, Islands, France, Germany, Ireland, Norway, Portugal, Sweden, UK, Poland, Spain, Italy, the Netherlands, Finland, Denmark and Switzerland) but also in the Falkland Islands and the United States, Canada, Japan (De Bossche, 2004; Gavier-Widen et al., 2005; Epstein, 2005; Le Dur et al., 2005; Buschmann et al., 2004a; Noremark and Hope, 2006; Konold et al., 2007; Luhken et al., 2007; EFSA, 2005; Saunders et al., 2006; Loiacono et al. , 2009)

Due to the low frequency of occurrence and the absence or poor representation of clinical signs, atypical scrapie is usually diagnosed during active surveillance in apparently healthy asymptomatic herds, and not in suspect clinical cases (Benestad et al., 2003; Konold, 2007). When present in flocks, atypical scrapie affects old sheep (older than 5 years). Considered a sporadic prion disease, it can be transmitted experimentally, in both ovinised transgenic mice and sheep (Le Dur et al., 2005; Simmons et al., 2007; 2011; Espinosa et al., 2009; Simmons et al., 2011).

Neuropathological and biochemical characteristics of atypical scrapie differ from those in classical scrapie. Affected sheep manifest ataxia as a predominant sign in the absence of pruritus. Other signs include anxiety and loss of body condition (Benestad et al., 2003). In terms of neuropathology, atypical scrapie is characterized by massive accumulation of $\mathrm{PrP}^{\mathrm{sc}}$ in cerebellum and cerebrum and their absence in DMSV at the level of obex. In some cases, $\operatorname{Prp}^{\text {Sc }}$ presence was detected in the nucleus of the spinal tract in the trigeminal nerve (Buschmann et al., 2004a; Orge et al., 2004; Epstein et al., 2005; Konold et al., 2007; Benestad, 2008; Nentwing et al., 2007). Several studies have shown that infectivity of the atypical scrapie reaches peripheral lymphoid tissues, from this point of view it being a threat to consumers (Simmons et al., 2011; Andreoletti et al., 2011; Benestad et al., 2003; Nentwing et al., 2007).

Biochemically, $\mathrm{PrP}^{\mathrm{Sc}}$ in atypical scrapie shows an electrophoretic profile after treatment with proteinase $\mathrm{K}$ that differs from the classical scrapie, with multiple bands and a characteristic band of low molecular weight (11-12 kDa and 7-8 $\mathrm{kDa}$ ) (Benestad et al., 2003; Arsac et al., 2007; Gretzschel et al., 2006; Klingeborn et al., 2006; Nentwing et al., 2007).

Genetically speaking, it seems that atypical scrapie resistance is completely opposite to classical scrapie. In atypical scrapie it seems that codon 141 (L / K) is involved in combination with alleles of haplotype 136/154/171. In these haplotypes, the highest frequency of occurrence of the disease is found in the following combinations: AFRQ (Moum et al., 2005; Saunders et al., 2006 and Luhken et al., 2007) ALRQ; ALHQ; ALRR; (Rodrigues-Martinez et al., 2007; Benestad et al., 2008; Hautaniemi et al., 2012), while haplotype VRQ is absent. The latest studies for discriminating prion strains involved in TSE in animals from those in humans have brought to light the similarity of molecular profile of isolates Nor98 (from Norway and Italy) with that characteristic for the GSS syndrome (Gerstmann-Straussler-Sheinker Syndrom) and that of the newly described human sporadic prion disorder, variably protease sensitive prionopathy (VPSPr), after treatment with $200 \mu \mathrm{g} /$ $\mathrm{ml}$ PK in WB analysis (Pirisinu et al., 2013).

Nor98 isolates contained highly PK resistant PrPres aggregates, with the main $\mathrm{PrP}^{\mathrm{res}}$ being a non-glycosylated internal fragment, cleaved at both the $\mathrm{N}$ and $\mathrm{C}$ termini, which represent the distinctive biochemical feature of Nor98. This biochemical signature, unique among animal 
TSEs, is reminiscent of PrPres observed in human prion disorders such as GSS and VPSPr (Pirisinu et al., 2013).

In the latest studies for the molecular discrimination of TSE agents, in classical scrapie the electrophoretic profile remains characterized by the same three fragments, corresponding to $\mathrm{N}$-terminally truncated diglycosylated, monoglycosylated and non-glycosylated PrPres, whatever the PK concentrations, while in the atypical scrapie the Nor98 profile is different depending on the PK concentrations (Pirisinu et al., 2013).

\section{Experimental scrapie}

Sheep can be experimentally infected with scrapie by using homogenised brain from affected animals as inoculum and administering it by several different routes including intracerebral, subcutaneous, oral and intravenous.

In sheep at least three distinct types of scrapie agents have been identified/isolated in the natural host: SSBP/1 (Dickinson et al., 1968), CH1641 (Foster and Dickinson, 1988), and Atypical scrapie agent (Benestad et al., 2003; Simmons et al., 2007).

As an example, with a source of scrapie known as SSBP/1 (Scrapie Sheep Brain Pool number 1) and in an experimental flock (the NPU Cheviot sheep), clinical signs were of short duration, usually only 2-3 weeks and the predominant sign was lack of co-ordination of gait, sometimes recumbency but with little accompanying pruritus (Hunter, 2003).

CH1641 strain had been propagated in sheep and was originally isolated from a British Cheviot sheep in 1971 (Foster et al., 1993).

BSE agent can also be transmitted experimentally to sheep, and the BSE agent in sheep showed similar molecular features with the experimental scrapie strain, CH1641 (Foster et al., 1993).

It is not known how many different strains of natural scrapie can exist although several studies are underway to try to find out using transmission of the disease to a panel of mouse lines and examining features such as incubation period, brain pathology and biochemistry.

\section{Experimental BSE}

BSE can also be transmitted to sheep by inoculation with affected bovine brain homogenate. Theoretically BSE could become endemic in the sheep population as has been demonstrated in experimentally infected sheep flocks, where BSE was seen to spread from ewe to lamb either in utero or at birth (Bellworty et al., 2008). This possibility of passing the BSE agent to sheep was suggested immediately after the BSE crisis in the UK, when a new form of Creutzfeld Jacobs disease appeared in humans (vCJD) demonstrating for the first time that the species barrier against prions is not absolute. However, no natural cases of BSE scrapie were recorded in sheep with a few exceptions to be discussed further.

Differentiation of infectious agents in animal prion diseases from those in humans soon became a crucial issue to resolve.

The first typical molecular signature of the BSE agent was established in Western blotting analysis of PrPres, to demonstrate the link between the infectious agent in BSE and the infectious agent in the variant form of Creutzfeldt-Jakob disease in humans, later confirmed by the analysis of the pathogenic behaviour of the infectious agent following transmission of the disease in wild-type mice (Baron and Biacabe, 2007).

After the BSE crisis, the classical BSE strain (BSE-C) led to over 200 cases of clinical human infectious variant CJD (***, 2012 - World Health Organization). Characterization of the BSE agent through transmission to wild type mice (e.g., C57B1 / 6 strain) proved a reliable method for differentiating BSE strains, due to the uniformity of profiles obtained from different sources infected with BSE, including cross-species transmitted ones (Vulin et al., 2012).

BSE agent in sheep showed similar molecular features with an experimental scrapie strain, CH1641 (Hope et al., 1999). This strain was propagated in sheep and was originally isolated from a British Cheviot sheep in 1971 (Foster et al., 1993) and then maintained by serial transmissions in sheep. CH1641 isolates might be the result of a transmission of L-type BSE to sheep or might represent similar isolates occurring in sheep (Baron et al., 1999). In this respect, scrapie sources CH1641, proved to be not transmissible to wild-type mice despite similarity of its biochemical properties to those of BSE strains.

In BSE scrapie the first accumulations of $\mathrm{PrP}^{\mathrm{sc}}$ were observed in the tonsil and the ileal Peyer's patches, followed by the draining lymph nodes and the spleen, and at a later stage, were detected 
in the CNS in the pre-ganglionic parasympathetic motor neurons of the DMNV (van Keulen, 2008).

Because natural cases of transmissions of BSE have been described in sheep and goats (Foster et al., 1993; Vulin et al., 2011), this evidence led to concern about the possible transmission of zoonotic BSE from sheep to human (Plinston et al., 2011).

Several natural scrapie cases were identified as "CH1641-like" natural scrapie isolates in sheep and goats, in the scrapie surveillance and control programme started in several European countries. For instance, a case of scrapie in goats was detected in 2005 in France, in which the molecular profile was similar to scrapie BSE in small ruminant (Eloit et al., 2005). A few cases of transmissible spongiform encephalopathies (TSEs) that showed partial similarities to experimental ovine BSE were also described in sheep. However, these natural isolates clearly differed from BSE by the presence of an additional band of approximately $14 \mathrm{kD}$, a C-terminally cleaved $\mathrm{PrP}^{\mathrm{res}}$ product, specifically recognized by a C-terminal antibody (SAF84) (Vulin et al., 2012). The Tg(OvPrP4) mouse line expressing the ovine prion protein proved to be a sensitive model for studying and identifying strains of agents responsible for scrapie and BSE (Bencsik and Baron, 2012).

PrnP gene polymorphisms in codon 129 which encodes methionine or valine, appear to be key factors involved in human susceptibility to prion diseases, in particular in the manifestation of vCJD disease, which was diagnosed in a patient homozygous for methionine, suffering from vCJD.

Regarding sheep, experimental infection with BSE is related to gene PrnP codon 168. A survival time three times higher was recorded in heterozygote ARL168QPrP sheep as compared to ARP168Q / ARP168Q homozygote ones (Houston et al., 2000; Hunter et al., 1996; Goldman et al., 2006).

\section{Prion protein (PrP) strains}

The first term to define causative agent of prion diseases was the slow virus, introduced by Bjorn Sigurdsson (1954) who worked on sheep scrapie in Iceland. In the following years, the infectious agent was assigned another names (virus or provirus). The term prion was introduced in 1982, by Stanley Prusiner, who studied the unusual properties of the infectious agent and proposed the prion hypothesis (Prusiner, 1982; 1984). According to this hypothesis, the cause of the TSEs is generally considered to be an abnormal form of prion protein $\left(\mathrm{PrP}^{\mathrm{C}}\right)$ codify by a cellular gene (PrnP).

The prions are infectious particles devoid of nucleic acids with a structure composed exclusively by modified proteins. The normal, cellular $\mathrm{PrP}^{\mathrm{C}}$ is converted into a pathogenic isoform $\mathrm{PrP}^{\mathrm{Sc}}$ (SC stands for the scrapie name, the first term used to define the pathological isoform) through a posttranslational process, during which it acquires high $\beta$-sheet, while $\operatorname{PrP}^{\mathrm{C}}$ is alpha-helix dominant. Infectious isolates exhibiting distinct incubation times and prion disease phenotype in the same host are defined as prion strains (Kovacs and Budka, 2009). The pathogen agents can be distinguished by their DNA differences; however, in the case of prions, the differences can be identified based on the different conformations of $\mathrm{PrP}$, which also include differential proteinase $\mathrm{K}$ digestion kinetics (Kovacs and Budka, 2009)

The mammalian PrP gene encodes a protein of approximately 250 amino acids that contains several distinct domains, including an $\mathrm{N}$-terminal signal peptide, a series of five proline and glycinerich octapeptide repeats, a central hydrophobic segment that is highly conserved, and a C-terminal hydrophobic region that is a signal for addition of a glycosyl-phosphatidylinositol (GPI) anchor (Byron, 2001). The $\operatorname{PrP}^{\mathrm{C}}$ is detergent soluble, sensitive to proteinase- $\mathrm{K}$ (PK) treatment, and has an endogenous truncated fragment. It is synthesized in the endoplasmic reticulum and processed by the Golgi apparatus, being found in the prion disease-unaffected brains. $\operatorname{PrP}^{\mathrm{C}}$ as a normal cellular protein is expressed in the neurons and glia of the brain and spinal cord, as well as in several peripheral tissues and in leukocytes (Caughey, 2001).

While $\operatorname{PrP}^{\mathrm{C}}(33-35 \mathrm{kDa})$ is completely digested after treatment with proteinase $\mathrm{K}, \mathrm{PrP}^{\mathrm{Sc}}$ (27-30kDa) is partly resistant to digestion, with an $\mathrm{N}$-terminal fragment of 62 amino acids being cut, leaving a core sequence of 141 amino acids. Depending on the TSE molecular type, PK removes 55-70 residues from the $\mathrm{N}$-terminal domain of $\mathrm{PrP}^{\mathrm{Sc}}$, leaving a distinct product PrPres, which consists of three major glycoforms: one unglycosilated, a monoglycosil and a di-glycosil fraction (Prusiner, 1984). The relative concentrations of the three 
glycoforms (glicosylation profile) are used as biochemical targets to distinguish between TSE strains (Collinge and Clarke, 2007; Hill et al., 1998; Thuring et al., 2004). In order to distinguish between the classical scrapie and the BSE scrapie, an electrophoretic profile with a lower unglycosilated band is obtained in BSE infected sheep. The electrophoretic profile in the experimental BSE scrapie is very similar to the CH1641 scrapie profile. The similar molecular weights obtained in natural scrapie isolates and in the experimental SSB1 isolates are also to be noted (Harris, 2003).

\section{Molecular TSE- typing}

In order to demonstrate the nature of nerve tissue aggregates, discrimination between the molecular type of scrapie isolates is the main diagnostic approach in scrapie. Promising results for discriminating other forms of classical scrapie diagnosis can be achieved using Western immunoblotting analysis. All Western immunoblotting techniques are based on detergent extraction followed by treatment with proteinase $\mathrm{K}$ enzyme to digest the host protein. In fact, WB is an effective technique for detection of the three glycoforms of PrPres with PrP-specific antibodies. In classical scrapie, the molecular pattern is characterised by three bands above 15 $\mathrm{kDa}$.

Molecular criteria used to discriminate BSE from scrapie are based on the low molecular weight of proteinase K-treated $\mathrm{PrP}^{\mathrm{Sc}}$ ( $\mathrm{PrP}^{\mathrm{res}}$ ), a high proportion of the diglycosylated $\mathrm{PrP}^{\mathrm{Sc}}$, and poor or absent binding with antibodies directed at N-terminal epitopes (Pirisinu et al., 2013). For atypical scrapie cases four protein bands are visualised by Western immunoblotting, ranging from $19 \mathrm{kDa}$ (unglycosylated PrPres) to $27 \mathrm{kDa}$ (diglycosylated PrPres) with a fourth band (lower than other TSEs) below $15 \mathrm{kDa}$ ( OIE, 2009).

\section{Genetics of scrapie disease}

Defining the mechanisms underlying the generation of $\mathrm{PrP}^{\mathrm{Sc}}$ from $\mathrm{PrP}^{\mathrm{C}}$ has become one of the central issues in understanding the pathogenesis of prion diseases.

The prionic protein gene belongs to a gene superfamily that comprises several orthologs (in many mammals and birds) and Doppel paralogs of gene PrnD (Prion Doppel Protein) (Moore et al., 1999) and SprnP (Shadoo Prion Protein) (Watts et al., 2007).

The gene is found on the $13^{\text {th }}$ ovine chromosome (31 kb) and is abbreviated PrnP. The encoding sequence of ovine PrnP gene (Lee et al., 1998) comprises 3 exons of 52, 98, and $4028 \mathrm{bp}$, separated by two introns of $2412 \mathrm{bp}$, and of 14031 bp. The two short exons are non-coding, and the long exon is coding, with an Open Reading Frame (ORF) comprising 236 codons. From the complete sequence, of $4178 \mathrm{bp}, 771 \mathrm{bp}$ represents the coding sequence of the prionic pre-protein.

Table 1. The risk intensity to develop ovine TSE related to the genotype, according to GB NSP *

\begin{tabular}{|c|c|c|}
\hline Risk class & Genotyp & Risk intensity \\
\hline I & ARR/ARR & Sheep highly resistant to scrapie \\
\hline II & $\begin{array}{l}\text { ARR/AHQ } \\
\text { ARR/ARH } \\
\text { ARR/ARQ }\end{array}$ & $\begin{array}{c}\text { Sheep resistant to scrapie, but which require a particular attention in breeding } \\
\text { programmes }\end{array}$ \\
\hline III & $\begin{array}{l}\text { ARQ/ARH } \\
\text { ARQ/AHQ } \\
\text { AHQ/AHQ } \\
\text { ARH/ARH } \\
\text { AHQ/ARH } \\
\text { ARQ/ARQ }\end{array}$ & $\begin{array}{l}\text { Sheep with low genetic resistance to scrapie. Their use in breeding programmes } \\
\text { must be avoided }\end{array}$ \\
\hline IV & $\mathrm{ARR} / \mathrm{VRQ}$ & Sheep sensitive to scrapie \\
\hline V & $\begin{array}{l}\text { AHQ/VRQ } \\
\text { ARH/VRQ } \\
\text { ARQ/VRQ } \\
\text { VRQ/VRQ }\end{array}$ & Sheep highly sensitive to scrapie which must be castrated or culled. \\
\hline
\end{tabular}


Of special interest for the Molecular Assisted Selection are codons 136, 154 and 171, which make up a haplotype encoding Alanine (A) or Valine (V) at codon 136; Arginine (R) or Histidine $(\mathrm{H})$ - at codon 154, and Glutamine (Q), Arginine (R) or Valine (V) at codon 171. The alleles from the three codons make up haplotypes with linked transmission, which form several genotypes classified into five risk classes (1-5) (Tab. 1).

Increased resistance to scrapie is associated with haplotype ARR and, conversely, increased susceptibility to scrapie is associated with haplotype VRQ. The alleles of the other three forms of PrnP haplotypes are ARQ, ARH and AHQ which have been associated with intermediate resistance to classical scrapie.

Codon variants at positions 136, 154, and 171 are not the only ones associated with resistance to scrapie. Other polymorphic codons that can be found in the PrnP gene are: M112T, A136V, M137T, S138N, L141F, H143R, H151C, R154H, P168L, R171QH, Q175E, R211G, P241S (Belt et al., 1995; DeSilva et al., 2003; Hunter et al., 2003; Goldmann et al., 2006; Moum et al., 2005; Maestrale et al., 2009). The breed factor is also intensely studied, which demonstrates a differentiated resistance of animals to scrapie.

As concerns subtype M112T in association with ARQ haplotype, it has been associated with susceptibility to scrapie in the US Suffolk breed (Laegrid et al. 2008; Heaton et al. 2010, Harington et al., 2010), and the variants of haplotype ARQ - M137T and N176K have been associated with scrapie resistance in intercranially-inoculated, orally-inoculated, and naturally-infected Italian Sarda breed sheep (Vaccari et al., 2007, 2009). The existence of some subtypes of the ARQ genotype resistant to scrapie opens up the possibility of MAS, without the presence of homozygote ARR/ ARR. In a study conducted in Ireland, it has been demonstrated that the sheep with ARQ/ARQ and ARQ/ARH genotypes presented the same risk of infection as the ones with VRQ/VRQ genotype (O'Doherty et al., 2002). Equally, the ovine diagnosed with scrapie in Germany, Spain and Greece were to a large extent carriers of genotype ARQ/ARQ (Billinis et al., 2004; Luhken et al., 2007).

In association studies, the $F$ variant of codon 141 has been strongly associated with atypical scrapie in Norwegian sheep, in combination with AHQ and ARQ alleles (Benestad et al., 2003;
Moum et al., 2005). In the UK, the AHQ allele was associated with the highest incidence of atypical scrapie and animals carrying homozygous or heterozygous combination of ARR, AHQ and AF141RQ or any one of these alleles when paired with ARQ as being susceptible to atypical scrapie (Saunders et al., 2006).

In an extensive study carried out in the USA on several breeds and crosses (Finnsheep, Dorset, Suffolk, Texel, Romanov, Romabouillet, Dorper, etc.), eight codons and an octapeptide repeats were associated with various forms of ovine diseases, i.e. codons 112, 136, 137, 154, 171, and 176 with classical scrapie; codons 141 and octapeptide insertion with atypical scrapie; and scrapie BSE with codon 168 (Heaton et al., 2010).

Scrapie control and elimination strategies based on genetic selection for resistance to classical scrapie have been deployed successfully in some countries. Recently, it was shown that reliance on only three PrP codon positions may not be sufficient to fully predict the susceptibility of sheep to TSE infection. For this purpose, breeding stock, particularly rams with appropriate genotype, can be selected to produce progeny with reduced risk of developing the disease, but these animals are not always common in flocks, and in some breeds the genotype is actually absent.

\section{CONCLUSIONS}

The situation of scrapie presence has been under active surveillance in EU Member States since 2002, when compulsory surveillance programmes have been imposed. Recognition of alleles associated with resistance to scrapie (ARR) favoured the implementation of MAS programmes since 1990 in several Member States, aimed at increasing frequencies of favourable alleles in populations and decreasing / eliminating alleles for susceptibility (i.e. VRQ). Over 10 years after their implementation (2002-2012), these strategies have produced their first effects. These are different in terms of the methods used and their effectiveness, taking into account the heterogeneity of temporal and spatial distribution of the disease. While in some member countries the decrease in the incidence of classical scrapie was statistically significant (6 Member States: Cyprus, France, Ireland, the Netherlands, Slovenia and the UK), in other 7 countries (Belgium, the Czech Republic, Greece, Italy, Romania, Slovakia 
and Spain) these differences were not statistically significant (EFSA, 2014).

Within the active surveillance programme, samples from apparently healthy animals slaughtered for consumption are subjected to rapid testing. Along the 10 years, 17 countries reported 4,132 cases of classical scrapie out of 4.7 million tested sheep (8.2 cases/10,000 rapid tests performed), and as for atypical scrapie, it was reported in 21 countries (without Romania), at a frequency of 5.8 cases/10,000 rapid tests performed. Over the same period, in some countries scrapie was reported sporadically (Bulgaria, Germany, Hungary and Portugal) or it was absent (Austria, Denmark, Estonia, Finland, Latvia, Lithuania, Luxemburg, Malta, Poland and Sweden).

Although the types of programmes applied in the 17 European countries were different, the effects of MAS were estimated depending on the prevalence of genotypes ARR/ARR in the entire sheep population over time. A minimum frequency of the ARR allele (53\%-100\%) was searched to estimate programme efficacy, where applied, the frequency being dependent on the country, breed and distribution of the disease at the national level (EFSA, 2014).

Although the elimination or the retention of some alleles in the population can have some negative effects on other traits due to the linkage phase between PrnP and other loci, these have been studied extensively, and not associations have been established (Vitezica et al., 2005; 2007). However, the introduction of classical scrapie selection as the major objective has led to a lower selection intensity on the other traits.

Monitoring the evolution of PrnP genotypes is an effective indicator of selection pressure, which is estimated in reference class animals along generations in order to avoid bias, while the evolution in the natural population is estimated based on mathematical models.

In countries where the decrease of scrapie incidence was statistically significant, the genetic selections programmes and the surveillance and control programmes were successfully applied. Cyprus reported an increase in ARR allele frequency from 0.40 to 0.99 and of ARR/ARR homozygote genotype frequency from 0.16 to 0.76 ; France from 0.49 to 0.85 (ARR/ARR from 0.26 to 0.72); Ireland from 0.86 to 0.998 (ARR/ARR: 0.62 -
0.84); the Netherlands: $0.36-0.70$ (ARR/ARR: 0.17-0.52); Slovenia 0.38-0.55 (ARR/ARR: 0.140.13); GB 0.5-0.69 (ARR/ARR: 0.29-0.54); Belgium 0.87-0.98 (ARR/ARR: 0.76-0.79); Czech Republic 0.53-0.85 (ARR/ARR: 0.22-0.51); Italy 0.47-0.70 (ARR/ARR: 0.23-0.25); Slovakia 0.39-0.4 (ARR/ ARR: 0.19-0.51) and Spain 0.28-0.48 (ARR/ARR: 0.11-0.25) (EFSA, 2014).

In some European countries, especially the ones where scrapie was rarely or never reported (such as Austria, Finland, Lithuania, etc.), the selection programmes started merely in 2012. In independently performed studies for testing the prevalence of ARR allele in Romania, where the selection programme also started in 2012, it has been found that the allele frequency is between 0.494-0.54 (Merino; Tigaie; Turcana), and the frequency of homozygotes is between 10.6\%17.3\% (Cosier et al., 2011).

\section{REFERENCES}

1. Andreoletti O, Berthon P, Marc D, Sarradin P, Grosclaude J, Van Keulen L, Schelcher F, Elsen JM, Lantier F, (2000), Early accumulation of PrPSc in gut-associated lymphoid and nervous tissues of susceptible sheep from a Romanov flock with natural scrapie. J. Gen. Virol., 81, 3115-3126.

2. Andreoletti O, Orge L, Benestad SL, Beringue V, Litaise C, et al. (2011) Atypical/Nor98 scrapie infectivity in sheep peripheral tissues. PLoS Pathog 7:e1001285.

3. Arsac JN, Betemps D, Morignat E, Feraudet C, Bencsik A, Aubert D, Grassi J, Baron T. Plos One (2009): 6; 4(10):e7300

4. Baron T, Biacabe AG.(2007). Molecular behaviors of "CH1641-Like" sheep scrapie isolates in ovine transgenic mice (Tg0vPrP4). J Virol:81(3) 7230-7.

5. Baron T, Madec J-Y, Calavas D, Richard Y, Barillet F (2000) Comparison of French natural scrapie isolates with bovine spongiform encephalopathy and experimental scrapie infected sheep. Neurosci Lett 284: 175-178.

6. Baron T, Vulin J, Biacabe AG, Lakhdar L, Verchere J, Torres JM, Bencsik A (2011). Emergence of classical BSE strain properties during serial passages of HBSE in wild-type mice. PLoS One, 6:e15839.

7. Baron TG, Biacabe AG, Bencsik A, Langeveld JP (2006) Transmission of new bovine prion to mice. Emerg Infect Dis 12:1125-1128.

8. Baron, T. G. M., J.-Y. Madec, and D. Calavas. (1999). Similar signature of the prion protein in natural sheep scrapie and bovine spongiform encephalopathy- linked diseases. J. Clin. Microbiol. 37:3701-3704

9. Baylis M, Houston F, Kao RR, McLean AR, Hunter N, et al. (2002) BSE - a wolf in sheep's clothing? Trends Microbiol 10: $563-570$. 
10. Bellworthy SJ, Dexter G, Stack M, Chaplin M, Hawkins SA, et al. (2005) Natural transmission of BSE between sheep within an experimental flock. Vet Rec 157: 206.

11. Bellworthy SJ, Dexter G, Stack M, Chaplin M, Hawkins SA, et al. (2008) Oral transmission of BSE to VRQ/VRQ sheep in an experimental flock. Vet Rec 162: 130-131.

12. Belt PB, Muileman, GM, Schreuder IH, Ruijter BEC, Gielkens JB, Smits MA. (1995). Identification of five allelic variants of the sheep PrP gene and their association with natural scrapie. Journal of General Virology 76, 509-517.

13. Bencsik A, Baron TG. (2012). Histopathological Studies of "CH1641-Like" Scrapie Sources Versus Classical Scrapie and BSE Transmitted to Ovine Transgenic Mice (TgOvPrP4). PloSOne, 6 (7), e22105

14. Bencsik A, Debeer S, Petit T, Baron T. (2009). Possible case of maternal transmission of feline spongiform encephalopathy in a captive cheetah. PLoS One 4, e6929.

15. Benestad SL, Arsac JN, Goldmann W, Noremark M. (2008). Atypical Nor98 scrapie: properties of the agent, genetics and epidemiology. Vet. ReS. 39 (4):19-33.

16. Benestad SL, Sarradin P, Thu B, Schönheit J, Tranulis MA, Bratberg B. (2003) Cases of scrapie with unusual features in Norway and designation of a new type, Nor98, Vet. ReS. 153:202-208.

17. Beringue V, Andréoletti O, Le Dur A, Essalmani R, Vilotte $\mathrm{J}$-L, et al. (2007) A bovine prion acquires an epidemic BSE strain-like phenotype upon interspecies transmission. J Neurosci 27: 6965-6971

18. Beringue V, Bencsik A, Le Dur A, Reine F, Lai TL, Chenais N, Tilly G, Biacabe AG, Baron T, Vilotte JL, Laude H (2006) Isolation from cattle of a prion strain distinct from that causing bovine spongiform encephalopathy.PLoS Pathog 2:e112.

19. Billinis C, Psychas V, Leontides L, Spyrou V, Argyroudis S, Vlemmas I, Leontides S, Sklaviadis T, Papadopoulos 0 (2004) Prion protein gene polymorphisms in healthy and scrapie-affected sheep in Greece. J Gen Virol 85:547-554

20. Bossers A, Harders FL, Smits MA. (1999). PrP genotype frequencies of the most dominant sheep breed in a country free from scrapie. Arch Virol 144, 829-834.

21. Bruce ME, Will RG, Ironside JW, McConnell I, Drummond D, Suttie A, McCardle L, Chree A, Hope J, Birkett C, Cousens S, Frase H, and Bostock CJ. (1997). Transmission to mice indicates that "new variant" CJD is caused by the BSE agent. Nature 389:498-501.

22. Bruce $\quad M, \quad$ Chree A, McConnell I, Foster J, Pearson G, Fraser H. (1994). Transmission of bovine spongiform encephalopathy and scrapie to mice: strain variation and the species barrier. Philos Trans $\mathrm{R}$ Soc Lond B Biol Sci.343:405-11.

23. Buschmann A, Biacabe AG, Ziegler U, Bencsik A, Madec JY, Erhardt G, Luhken G, Baron T, Groshup MH. (2004a). Atypical scrapie cases in Germany and France are identified by discrepant reaction pattern in BSE rapid test. J Virol Methods. 117(1): 27-36

24. Buschmann A, Lühken G, Schultz J, Erhardt G, Groschup MH. (2004b) Neuronal accumulation of abnormal prion protein in sheep carrying a scrapie resistant genotype (PrPARR/ARR), J. Gen. Virol, 85:2727-2733.

25. Byron Caughey, Prion Proteins, 1 st Edition, Academic Press (20010, eBook ISBN:97800804933982001; 405 pp

26. Campeanu MV. (2001), Encefalopatiile spongiforme transmisibile, Ed. Viața Medicală Românească

27. Capobianco R, Casalone C, Suardi S, Mangieri M, Miccolo C, et al. (2007) Conversion of the BASE prion strain into the BSE strain : the origin of BSE? PLoS Pathog 3: 1-8. doi:10.1371/journal.ppat.0030031.

28. Capucchio MT, Guarda F, Pozzato N, Coppolino S, Caracappa S, DiMarco V (2001) Clinical signs and diagnosis of scrapie in Italy: a comparative study in sheep and goats. J Vet Med A Physiol Pathol Clin Med, 48:23-31.

29. Casalone C, Zanusso G, Acutis P, Ferrari S, Capucci L, Tagliavini F, Monaco S, Caramelli M. (2004).Identification of a second bovine amyloidotic spongiform encephalopathy: molecular similarities with sporadic Creutzfeldt-Jakob disease. Proc Natl Acad Sci USA, 101:3065-3070.

30. Catoi C, Baba AI, Gal A, Taulescu MA, Rus IV, Bolfa P. (2008). The diagnosis of scrapie in a flock of sheep.Lucrari Stiintifice, Med Vet, Xli:271-277

31. Collinge J, Clarke AR. (2007). A general model of prion strains and their pathogenicity. Science, 318: 930-6

32. Collinge J, Sidle KCL, Meads J, Ironside J, Hill AF (1996) Molecular analysis of prion strain variation and the aetiology of 'new variant' CJD. Nature 383: 685-690.

33. Cosier V, Vlaic A, Miresan V, Constantinescu R (2011). The genetic resistance of rams from Turcana breed to Ovine Transmissible Spongiform Encephalopathy (scrapie), RBL, 16(4): 6328-6335

34. Coşier Viorica (coordinator), Creșterea rezistenței la scrapie în populațiile de ovine din România prin selecția asistată la nivel molecular, 2007, Vol I, Ed. Risoprint ClujNapoca, ISBN: 978-973-751-578-0; ISBN specific: 978973-571-579-7

35. De Bosschere H, Roels S, Benestad SL, Vanopdenbosch E. (2004), Scrapie case similar to Nor98 diagnosed in Belgium via active surveillance. Vet Rec, 155:707-708.

36. Detwiler LA, Baylis M. (2003). The epidemiology of scrapie. In: Risk Analysis of BSE and TSEs: Update on BSE and the Use of Alternative to MBM as Protein Supplements. Revue Scientifique et Technique. Office International des Epizooties (OIE), Paris. 22: 121-143.

37. Dickinson AG, Meikle VM, Fraser H. (1968b). Identification of a gene which controls the incubation period of some strains of scrapie agent in mice. J comp Pathol, 78 (3): 293-9

38. Dickinson AG, Stamp JT, Renwich CC, Rennie JC. (1968a). Some factors controlling the incidence of scrapie in Cheviot sheep injected with a Cheviot -passage scrapie agent. J comp Pathol,78(3): 313-21

39. EFSA, Joint Scientific Opinion on any possible epidemiological or molecular association between TSEs in animals and humans. EFSA Journal 2011; 9(1):1945

40. ESFA, Scientific Opinion on the scrapie situation in the EU after 10 years of monitoring and control in sheep and goat; EFSA Journal 2014;12(7):3781 
41. EFSA, Opinion of the scientific panel on biological hazards on the request from the European Commission on classification of atypical transmissible spongiform encephalopathy (TSE) cases in small ruminants. EFSA J, 276:1-30.

42. Eiden M, Hoffmann C, Balkema-Buschmann A, Müller M, Baumgartner K, Groschup MH, (2010), Biochemical and immunohistochemical characterization of feline spongiform encephalopathy in a German captive cheetah. J Gen Virol, 91:2874-2883.

43. Eloit M, Adjou K, Coulpier M, Fontaine J-J, Hamel R, et al. (2005) BSE agent signatures in a goat. Vet Rec, 156: 523 524.

44. Epstein V, Pointing S, Halfacre S (2005) Atypical scrapie in the Falkland Islands. Vet Rec 19:667-668

45. Espinosa JC, Herva ME, Andreoletti O, Padilla D, Lacroux C, Cassard H, Lantier I, Castilla J, Torres JM(2009). Transgenic mice expressing porcine prion protein resistant to classical scrapie but susceptible to shep bovine spongiform encephalopathy and atypical scrapie. Emerg Infect Dis., 15 (8):1214-21.

46. Ferguson NM, Donnelly CA. (2003). Assessment of the risk posed by bovine spongiform encephalopathy in cattle in Great Britain and the impact of potential changes to current control measures. Proc. R. Soc. B 270, 1579-1584.

47. Foster J, Hunter N. (1998). Transmissible Spongiform Encephalopaties: transmission, mechanism of disease, and persistence. Curr Opin Microbiol, 1 (4): 442-7

48. Foster JD, Dickinson AG (1988) The unusual properties of CH1641, a sheep-passaged isolate of scrapie. Vet Rec, 123:5-8

49. Foster JD, Hope J, Fraser H (1993) Transmission of bovine spongiform encephalopathy to sheep and goats. Vet Rec 133: 339-341.

50. Gavier-Widen D, Stack MJ, Baron T, Balachandran A, Simmons M (2005) Diagnosis of transmissible spongiform encephalopathies in animals: A Review. J Vet Diagn Invest, 17:509-527

51. Goldmann W, Houston F, Stewart P, Perucchini M, Foster J, Hunter N (2006). Ovine prion protein variant A(136) $\mathrm{R}(154) \mathrm{L}(168) \mathrm{Q}(171)$ increases resistance to experimental challenge with bovine spongiform encephalopathy agent. J Gen Virol, 87 (12): 3741-3745

52. Gonzalez L, Martin S, Houston FE, Hunter N, Reid HW, Bellworthy SJ, Jeffrey M. (2005). Phenotype of diseaseassociated PrP accumulation in the brain of bovine spongiform encephalopathy experimentally infected sheep. J Gen Virol, 86: 827-838

53. Gretzschel A, Buschmann A, Langeveld J, Groschup MH. (2006). Immunological characterization of abnormal prion protein from atypical scrapie cases in sheep using a panel of monoclonal antibodies. J Gen Virol. 87(12): 371522

54. Groschup MH, Lacroux C, Buschmann A, Lühken G, Mathey J, Eiden M, Lugan S, Hoffmann C, Espinosa JC, Baron T, Torres JM, Erhardt G, and Andreoletti O. (2007) Classic scrapie in sheep with the ARR/ARR prion genotype in Germany and France. Emerg Infect Dis. Aug;13(8):1201-7.
55. Harrington NP, O’Rourker KI, Feng Y, Rendulich J, Difruscio C, Balachandran A (2010). Prion genotype of scrapie infected Canadian sheep 1998-2008. Can J Vet Res, 74(3):228-32

56. Harris DA. (2003). Trafficking, turnover and membrane topology of PrP. Br Med Bull, 66:71-85.

57. Heaton MP, Leymaster KA, Kalbfleisch TS, Freking BA, Smith TP, Claw-son ML, Laegreid WW. (2010). Ovine reference materials and assays for prion genetic testing. BMC Vet Res, 30:6-23.

58. Hill AF, Desbruslais M, Joiner S, Sidle KCL, Gowland I, Collinge J. (1997). The same prion strain causes vCJD and BSE. Nature, 389: 448-450.

59. Hill AF, Sidle KCL, Joiner S, Keyes P, Martin TC, et al. (1998) Molecular screening of sheep for bovine spongiform encephalopathy. Neurosci Lett 255: 159-162.

60. Hope J, Wood SC, Birkett CR, Chong A, Bruce ME, Cairns D, Collinge J. (1999). Molecular analysis of ovine prion protein identifies similarities between BSE and an experimental isolate of natural scrapie, CH1641. J Gen Virol; 80 (1):1-4; PMID:993467

61. Hope J. (2000). Prions and neurodegenerative disease. Curr Opin Gen Dev, 10: 568-574.

62. Houston F, Foster JD, Chong A, Hunter N, Bostock CJ (2000). Transmission of BSE by blood transfusion in sheep. Lancet, 356:999-1000

63. Houston F, Goldmann W, Foster J, Gonzalez L, Jeffrey M, Hunter N. (2015). Comparative susceptibility of sheep of different origins, breeds and PrnP genotypes to Challenge with Bovine Spongiform Encephalopaty and scrapie. Plos One, journal.pone.0143251, 1-17

64. Hunter N, Foster JD, Benson G, Hope J. (1991). Restriction fragment length polymorphisms of the scrapie-associated fibril protein (PrP) gene and their association with susceptibility to natural scrapie in British sheep. Journal of General Virology 72, 1287-1292.

65. Hunter N, Foster JD, Goldmann W, Stear MJ, Hope J, Bostock C. (1996) Natural scrapie in a closed flock of Cheviot sheep occurs only in specific PrP genotypes, Arch. Virol. 141:809-824.

66. Hunter N, Cairns D. (1998). Scrapie-free Merino and Poll Dorset sheep from Australia and New Zealand have normal frequencies of scrapie-susceptible PrP genotypes. J Gen Virol, 79 (8):2079-82.

67. Hunter N. (2003). Scrapie and experimental BSE in sheep. British Med Bull, 66: 171-183

68. Jeffrey M and Gonzalez L. (2007). Classical sheep transmissible spongiform encephalopathies: pathogenesis, pathological phenotypes and clinical disease. Neuropathol and Applied Neurobiol. 33(4): 373394

69. Jeffrey M, Martin S, Chianini F, EatoN S, Dagleish MP , Gonzlez L. (2014). Incidence of Infection in Prnp ARR/ ARR Sheep following Experimental Inoculation with or Natural Exposure to Classical Scrapie. plOS One, 9 (3): e91026

70. Jeffrey M, Martin S, Gonzalez L, Foster J, Langeveld JP, et al. (2006) Immunohistochemical features of 
$\operatorname{PrP}(d)$ accumulation in natural and experimental goat transmissible spongiform encephalopathies. J Comp Pathol. 134:171-181

71. Jeffrey M, Ryder S, Martin S, Hawkins SA, Terry L, BerthelinBaker C, Bellworthy SJ.(2001). Oral inoculation of sheep with the agent of bovine spongiform encephalopathy (BSE). 1. Onset and distribution of disease-specific PrP accumulation in brain and viscera. J. Comp. Pathol. 124, 280-289.

72. Klingeborn M, Wik L, Simonsson M, Renstrom LHM, Ottinger T, Linne T. (2006). Characterization of proteinase K-resistant N- and C-terminally truncated PrP in Nor98 atypical scrapie. J Gen Virol, 87, 1751-1760

73. Konold T, Davis A, Bone G, Bracegirdle J, Everitt S, Chaplin M, Saunders GC, Cawthraw S, Simmons MM, (2007), Clinical findings in two cases of atypical scrapie in sheep: a case report. BMC Vet Res, 3:2.

74. Kovacs GG, Budka H (2009) Molecular Pathology of Human Prion Diseases. Int. J. Mol. Sci., 10, 976-999

75. Kuczius T, Haist I, Groschup MH (1998) Molecular analysis of bovine spongiform encephalopathy and scrapie strain variation. J Infect Dis 178:693-699.

76. Laegreid WW, Clawson ML, Heaton MP, Green BT, O’Rourke KI, Knowles DP (2008). Scrapie resistance in ARQ sheep. J Virol, 82(20):10318-10320.

77. Laegrid WW, Clawson ML, Knowles DP. (2008). Scrapie resistance in ARQ sheep. J Virol, 82 (20): 10318-10320

78. Le Dur A, Beringue V, Andreoletti O, Reine F, Lai TL, et al. (2005) A newly identified type of scrapie agent can naturally infect sheep with resistant PrP genotypes. Proc Natl Acad Sci USA 102: 16031-16036.

79. Lee IY, Westaway D, Smit AFA, Wang K, Seto J, Chen L, Acharya C, Ankener M, Baskin D, Cooper C, Yao H, Prusiner S, Hood L. (1998). Complete Genomic Sequence and Analysis of the Prion Protein Gene Region from Three Mammalian Species. Genome Res. 8: 1022-1037

80. Liberski PP, Jaskólski M (2002) Dual view of prion hypothesis. Acta Neurobiol Exp. 62:197-226

81. Loiacono CM, Thomsen BV, Hall SM, Kiupel M, Sutton D, O’Rourke K, Barr B, Anthenill L, Keane D. (2009). Nor98 scrapie identified in the United States. J. Vet. Diag. Invest., $21,454-463$.

82. Luhken G, Buschmann A, Brandt H, Eiden M, Groschup MH, Erhardt G. ( 2007 ) Epidemiological and genetical differences between classical and atypical scrapie cases. Vet Res.;38:65-80.

83. Maestrale C, Carta A, Attene S, Galistu A, Santuciu C. (2009). p.Asn176Lys and p.Met137Thr dimorphisms of the PRNP gene significantly decrease the susceptibility to classical scrapie in ARQ/ARQ sheep. Anim. Genet. 40:982985.

84. Moore SJ, Simmons MM, Chaplin MJ, Spiropoulos J. (2008). Neuroanatomical distribution of abnormal prion protein in naturally occurring atypical scrapie cases in Great Britain. Acta Neuropathologica 116, 547- 559.

85. Moum T, Olsaker I, Hopp P, Moldan T, Valheim M, Moum T, Benestatd SL. (2005), Polymorphisms at codons 141 and
154 in the ovine prion protein gene are associated with scrapie Nor98 cases. J Gen Virol., 86, 231-235.

86. Nentwig A, Oevermann A, Heim D, Botteron C, Zellweger K, Drögemüller C, Zurbriggen A, Seuberlich T (2007) Diversity in neuroanatomical distribution of abnormal prion protein in atypical scrapie. PLoS Pathog 3:e82

87. Noremark M, Hopp P. (2006). Reported occurrence of atypical scrapie in Europe. Proceedings of the 11th Symposium of the International Society for Veterinary Epidemiology and Economics, Cairns, Australia: ISVEE 11, 1030

88. O’Doherty E, Healy A, Aherne M, Hanrahan JP, Weavers E, Doherty M, Roche JF, Gunn M, Sweeney T. (2002). Prion protein (PrP) gene polymorphisms associated with natural scrapie cases and their flock-mates in Ireland. Res Vet Sci 73, 243-250

89. O’Rourke KI, Baszler TV, Miller JM, Spraker TR, Sadler Riggleman I, Knowles DP. (1998). Monoclonal antibody F89/ 160.1.5 defines a conserved epitope on the ruminant prion protein. J Clin Microbiol 36, 1750-1755

90. Oesch B, Westaway D, Wa'Ichli M, McKinley MP, Kent SBH, Aebersold R, Barry RA, Tempst T, Teplow DB, Hood LE, Prusiner SB, Weissmann, C. (1985). A cellular gene encodes scrapie PrP27-30 protein. Cell 40:735-746.

91. OIE Terrestrial Manual (2009). Chapter: 2.7.13. - Scrapie

92. Orge L, Galo A, Machado C, Lima C, Ochoa C, Silva J, Ramos M, Simas JP. (2004), Identification of putative atypical scrapie in sheep in Portugal, J. Gen. Virol 85:3487-3491

93. Peet Rl, Curran JM (1992). Spongiform encephalopaty in an imported cheetah (Acinonex jubatus). Austral Vet Rec, 131:307-310.

94. Pirisinu L, Nonno R, Esposito L, Benestad S, Gambetti P, Agrimi U, Zou W-Q. (2013). Small Ruminant Nor98 Prions Share Biochemical Features with Human GerstmannStraussler-Scheinker Disease and Variably ProteaseSensitive Prionopathy. Plos One, 8 (6): e66405

95. Plinston C, Hart P, Chong A, Hunter N, Foster J, Piccardo P, Manson JC, Barron RM (2011). Increased susceptibility of human-PrP transgenic mice to bovine spongiform encephalopathy following passage in sheep. J Virol, 85:1174-1181.

96. Prusiner SB (1982), Novel proteinaceous infectious particles cause scrapie. Science 216:136-144.

97. Prusiner SB, Groth DF, Bolton DC, Kent SB, Hood LE (1984). Purification and structural studies of a major scrapie prion protein. Cell 38:8322-8327.

98. Prusiner SB, Scott MR, DeArmond SJ, Cohen FE. (1998). Prion protein biology. Cell 93:337-348

99. Rodriguez-Martinez AB, Garrido JM , Maza S, Benedicto L, Geijo M, Gomez N , Minguijon E, Benestad SL , Juste RA. (2007). Atypical/Nor98 scrapie in the Basque Country: a case report of eight outbreaks. BMC Vet Res, 6(17): 1-9

100. Saunders GC, Cawthraw S, Mountjoy SJ, Hope J, Windl O. (2006). PrP genotypes of atypical scrapie cases in Great Britain. J Gen Virol., 87, 3141-3149.

101. Schneider K, Fangerau H, Michaelsen B, Raab WHM (2008) The early history of the transmissible spongiform 
encephalopathies exemplified by scrapie. Brain Res Bull 77:343-355

102. Scott JR. (1993). Scrapie pathogenesis, Br Med Bull., 49(4):778-91.

103. Sigurdson CJ, Joshi-Barr S, Bett C, Winson O, Manco G, Schwarz P, Rülicke T, Nilsson KP, Margalith I, Raeber A, Peretz D,Hornemann S, Wüthrich K, Aguzzi A. (2011). Spongiform encephalopathy in transgenic mice expressing a point mutation in the $\beta 2-\alpha 2$ loop of the prion protein, J Neurosci. 28;31(39):13840-7.

104. Simmons MM, Konold T, Simmons HA, Spencer YI, Lockey R, et al. (2007) Experimental transmission of atypical scrapie to sheep. BMC Vet Res 3: 20.

105. Simmons MM, Moore SJ, Konold T, Thurston L, Terry LA, et al. (2011) Experimental oral transmission of atypical scrapie to sheep. Emerg Infect Dis 17:848-854.

106. Stack J, Chaplin MJ, Clark J (2002) Differentiation of prion protein glycoforms from naturally occurring sheep scrapie sheep-passaged scrapie strains (CH1641 and SSBP1) bovine spongiform encephalopathy (BSE) cases and Romney and Cheviot breed sheep experimentally inoculated with BSE using two monoclonal antibodies. Acta Neuropathol 104: 279-286.

107. Stack M, Gonzalez L, Jeffrey M, Martin S, Macaldowie C, et al. (2009) Three serial passages of bovine spongiform encephalopathy in sheep do not significantly affect discriminatory test results. J Gen Virol 90: 764-768.

108. Thuring CM, Erkens JHF, Jacobs JG, Bossers JG, van Keulen LJM, et al. (2004) Discrimination between scrapie and bovine spongiform encephalopathy in sheep by molecular size immunoreactivity and glycoprofile of prion protein. J Clin Microbiol 42: 972-980. “CH1641Like" Sheep Scrapie and L-Type BSE

109. Vaccari G, D'Agostino C, Nonno R, Rosone F, Conte M, Di Bari MA,Chiappini B, Esposito E, De Grossi L, Giordani F, et al. (2007). Prion protein alleles showing a protective effect on the susceptibility of sheep to scrapie and bovine spongiform encephalopathy. J Virol, 81(13):7306-7309

110. Vaccari G, Scavia G, Sala M, Cosseddu G, Chiappini B, Conte M, Esposito E, Lorenzetti R, Perfetti G, Marconi P, et al.(2009). Protective effect of the AT137RQ and ARQK176 PrP allele against classical scrapie in Sarda breed sheep.Vet Res, 40(3):19.24

111. Vitezica ZG, Moreno CR, Bouix J, Barillet F, Perret G and Elsen JM, 2005. A study on associations between PrP genotypes and meat traits in French sheep breeds. Animal Science, 81, 325-330.

112. Vitezica ZG, Moreno CR, Bodin L, Francois D, Barillet F, Brunel JC and Elsen JM, 2006. No associations between PrP genotypes and reproduction traits in INRA 401 sheep. Journal of Animal Science, 84, 1317-1322.

113. Vitezica ZG, Moreno CR, Lantier F, Lantier I, Schibler L, Roig A, Francois D, Bouix J, Allain D, Brunel J-C, Barillet $\mathrm{F}$ and Elsen J-M, 2007. Quantitative trait loci linked to
PRNP gene controlling health and production traits in INRA 401 sheep. Genetics Selection Evolution, 39, 421430.

114. Van Keulen LJM, Vromans AE, Dolstra CH, Bossers A, van Zijderveld FG, (2008) Pathogenesis of bovine spongiform encephalopathy in sheep. Arch Virol 153:445-453

115. Vulin J, Biacabe AG, Cazeau G, Calavas D, Baron T (2011). Molecular typing of protease-resistant prion protein in transmissible spongiform encephalopathies of small ruminants, France, 2002-2009. Emerg Infect Dis, 17:5563.

116. Vulin J, Beck KE, Bencsik A, Lakhdar L, Spiropoulos J, Baron T.(2012). Selection of distinct strain phenotypes in mice infected by ovine natural scrapie isolates similar to CH1641 experimental scrapie. J Neuropathol Exp Neurol. 71(2):140-7.

117. Watts JC, Drisaldi B, Ng V, Yang J, Strome B, Horne P, Sy MS, Yoong L, Young R (2007). The CNS glycoprotein Shadoo has $\operatorname{PrP}(\mathrm{C})$-like protective properties and displays reduced levels in prion infections. EMBO J 26, 4038-4050

118. Wells GA, Scott AC, Johnson CT, Gunning RF, Hancock RD. (1987). A novel progressive spongiform encephalopathy in cattle. Vet Rec 121: 419-420.

119. Westergard L, Turnbaugh JA, Harris DA. (2011). A nine amino acid domain is essential for mutant prion protein toxicity, J Neurosci. 28;31(39):14005-17.

120. Wilesmith JW, Ryan JB, Atkinson MJ. (1991). Bovine spongiform encephalopathy: epidemiological studies on the origin. Ver Res, 128(9): 199-203

121. Wilesmith JW, Wells GA, Cranwell MP, Ryan JB. (1988). Bovine spongiform encephalopathy: epidemiological studies, Ver Res, 123: 638-644

122. Will RG, Ironside JW, Zeidler M, Cousens SN, Estibeiro K, Alperovitch A, Poser S, Pocchiari M, Hofman A, Smith PG. (1996). A new variant of Creutzfeldt-Jakob disease in the UK. Lancet 347:921-925.

123. Will RG. (2003) Acquired prion disease: iatrogenic CJD, variant CJD, kuru. Br. Med. Bull., 66, 255-265.

124. Willoughby K, Kelly DF, Lyon DG, Wells GHA. (1992), Spongiform encephalopathy in a captive puma (Felis concolor). Veterinary Record, 131: 431-434.

125. World Health Organization. Accessed 03.12.2016

126. www/ec.europa.eu/food/fs/bse/bse28_en.html Decision 2000/766/EC

127. *** http://www.mpi.govt.nz (2016) New Zealand's Position with Regards to Scrapie

128.***, 2011, Report on the monitoring and testing of ruminants for the presence of Transmissible Spongiform Encephalopathy (TSE) in the EU in 2010

129. ***,www.who.int/mediacentre/factsheets/fs180/en/ Fact sheet No 180, Revised February 2012. 